\title{
LA HUELGA GENERAL DE 1913: CRISIS ECONÓMICA, REPRESIÓN ESTATAL Y DIVISIÓN DEL MOVIMIENTO OBRERO
}

\author{
Alejandro Belkin* \\ CONICET - UBA / Centro de Estudios \\ Recibido: 30 de junio de 2021 \\ Históricos de los Trabajadores y las Izquierdas \\ Aceptado: 22 de septiembre de 2021 \\ $\bowtie$ ambelkin@gmail.com \\ DOI: 10.46553/colec.32.2.2021.p163-194
}

Resumen: En la Argentina, en la primera década del siglo XX, se proclamaron nueve huelgas generales nacionales. En contraste con lo sucedido en el primer decenio, en la segunda década del siglo XX fueron declaradas apenas dos huelgas generales, en 1913 y 1919. El paro nacional, como forma de lucha habitual del movimiento obrero, despareció del horizonte político de las organizaciones gremiales. El período comprendido entre el Centenario y la primera presidencia de Yrigoyen representa una fase de transición en varios sentidos. A nivel de la estructura económica, del régimen político y de la orientación ideológica del movimiento obrero. En este artículo nos hemos propuesto analizar la olvidada huelga general de 1913, haciendo hincapié en las razones que la motivaron, las disputas dentro del movimiento obrero, sus alcances y consecuencias.

Palabras clave: Sindicalismo; anarquismo; socialismo; huelga general; Argentina

Abstract: In Argentina, in the first decade of the 20th century, nine national general strikes were declared. In contrast to what happened in the first decade, in the second decade of the twentieth century only two

\footnotetext{
${ }^{*}$ Doctor en Historia por la Facultad de Filosofía y Letras de la Universidad de Buenos Aires (UBA) y becario posdoctoral del Consejo Nacional de Investigaciones Científicas y Técnicas (CONICET), con lugar de trabajo en el Instituto de Investigaciones en Humanidades y Ciencias Sociales (IdIHCS).

Agradezco el minucioso y agudo trabajo realizado por los/as evaluadores/as, sus comentarios y sugerencias permitieron mejorar la factura del presente artículo.
} 
general strikes were declared, in 1913 and 1919. The national strike, as a habitual form of struggle of the labor movement, disappeared from the political horizon of the union organizations. The period between the Centennial and the first Yrigoyen presidency represents a transitional phase in several ways. At the level of the economic structure, the political regime and the ideological orientation of the labor movement. In this article we have proposed to analyze the forgotten general strike of 1913, emphasizing the reasons that motivated it, the disputes within the labor movement, its scope and consequences.

Keywords: Syndicalism; Anarchism; Socialism; General Strike; Argentina

\section{Introducción}

En 1902, en la Argentina, se inició un nuevo ciclo de protestas obreras ${ }^{1}$, caracterizado por grandes huelgas generales, en la primera década del siglo XX se declararon nueve paros nacionales (Andreassi 1991; Lobato y Suriano 1990; Santella 2000). Este período, signado por una alta conflictividad social, fue clausurado violentamente en vísperas del Centenario, la represión estatal y paraestatal diezmó a las organizaciones obreras (Iñigo Carrera 2013). La ley de Defensa Social, aprobada en junio de 1910, estableció un marco jurídico profundamente restrictivo para el accionar de las organizaciones gremiales, una suerte de estado de sitio permanente para las sociedades obreras (Costanzo 2007; Franco 2019; Zimmermann 1995). En contraste con lo sucedido en el primer decenio, en la segunda década del siglo XX fueron declaradas apenas dos huelgas generales, en 1913 y 1919. El paro nacional, como forma de lucha habitual del movimiento obrero, despareció del horizonte político de las organizaciones gremiales. En los años posteriores al Centenario, las centrales sindicales asumieron una actitud mucho más cautelosa, evitando

\footnotetext{
${ }^{1}$ En noviembre de 1902 tuvo lugar en la Argentina la primera huelga general (Boido 2002), este acontecimiento marcó un hito en la historia del movimiento obrero (Iñigo Carrera 2000). A partir de este suceso, se inició un ciclo de creciente conflictividad gremial, que se extendió - con altibajos- hasta mayo de 1910 (Korzeniewicz 1989; 1995).
} 
medidas de fuerza que paralizaran el país. En este artículo nos hemos propuesto analizar la huelga general de 1913, haciendo hincapié en las razones que la motivaron, las disputas dentro del movimiento obrero, sus alcances y consecuencias.

\begin{tabular}{|c|c|c|c|}
\hline \multicolumn{4}{|c|}{ Cuadro 1. Huelgas generales en la primera década del siglo $\mathrm{XX}$} \\
\hline \# & Año & Mes & Observaciones \\
\hline 1 & 1902 & noviem. & $\begin{array}{l}1^{\circ} \text { huelga general nacional. En solidaridad con los } \\
\text { trabajadores del puerto de Buenos Aires. Convocó } \\
\text { la FOA, el PS se opuso. }\end{array}$ \\
\hline 2 & 1904 & diciemb. & $\begin{array}{l}\text { En solidaridad con los trabajadores asesinados en } \\
\text { Rosario, convocó la FORA, adhieren la UGT y el } \\
\text { PS. }\end{array}$ \\
\hline 3 & 1905 & octubre & $\begin{array}{l}\text { Contra el estado de sitio. La UGT convocó por } 48 \\
\text { hs, adhirió el PS. La FORA declaró la huelga } \\
\text { general por tiempo indeterminado. }\end{array}$ \\
\hline 4 & 1907 & enero & $\begin{array}{l}\text { En solidaridad con los trabajadores rosarinos. } \\
\text { Convocan la FORA y la UGT de manera conjunta, } \\
\text { el PS toma distancia. }\end{array}$ \\
\hline 5 & 1907 & agosto & $\begin{array}{l}\text { En repudio al asesinato de trabajadores en } \\
\text { Ingeniero White, convocan la FORA y la UGT, } \\
\text { por separado. }\end{array}$ \\
\hline 6 & 1908 & enero & $\begin{array}{l}\text { Contra la deportación de dirigentes obreros. } \\
\text { Convocada por la FORA, con la oposición de la } \\
\text { UGT }\end{array}$ \\
\hline 7 & 1909 & mayo & $\begin{array}{l}\text { En repudio por la masacre en Plaza Lorea, } \\
\text { convocan la FORA y la UGT de manera conjunta, } \\
\text { adhiere el PS. }\end{array}$ \\
\hline 8 & 1909 & octubre & $\begin{array}{l}\text { En repudio al asesinato de Francisco Ferrer, } \\
\text { convocan por separado las FORA y la CORA. }\end{array}$ \\
\hline 9 & 1910 & mayo & Declarada por la CORA y secundada por la FORA \\
\hline
\end{tabular}


La historia del movimiento obrero de la primera década del siglo XX, sus organizaciones gremiales, corrientes políticas y movimientos de protesta, ha sido abordado por diferentes autores y desde muy diversas perspectivas (Barrancos 1990; Bilsky 1985; Godio 1972; Martínez Mazzola 2011; Poy 2014; Suriano 1988) Sin embargo, no ha sucedido lo mismo con el sexenio siguiente. El período comprendido entre el Centenario y la asunción de Yrigoyen a la presidencia ha sido descuidado por la historiografía especializada ${ }^{2}$. La debilidad de las organizaciones gremiales y la ausencia de grandes conflagraciones sociales quizás explique la falta de interés por el movimiento obrero de estos años. Los estudios sobre los trabajadores, sus organizaciones y sus luchas, cobran nueva relevancia a partir de 1916 (Ceruso 2015; Garguin 2000; Gordillo 1988; Horowitz 2015; Monserrat 2011; Palermo 2009). Por lo tanto, este artículo pretende realizar una contribución para cubrir este enorme vacío historiográfico.

En nuestra investigación hemos utilizado diversos tipos de fuentes. En primer lugar, relevamos las publicaciones de las principales corrientes políticas, el periódico socialista La Vanguardia, el cotidiano ácrata $L a$ Protesta y el periódico sindicalista revolucionario La Acción Obrera. Además, consultamos diarios comerciales y fuentes estatales, como La Nación y el Boletín del Departamento Nacional del Trabajo. También accedimos a fuentes inéditas, muy poco transitadas, nos referimos a los libros de actas del Consejo Federal de la Federación Obrera Regional Argentina (FORA) y del Consejo Confederal de la Confederación Obrera Regional Argentina (CORA). Estos materiales nos proporcionaron información muy valiosa sobre los debates internos dentro de ambas centrales obreras. La diversidad de fuentes consultadas, políticas, gremiales, comerciales y estatales, nos permitieron realizar una exhaustiva reconstrucción historiográfica.

2 Entre las producciones académicas, apenas contamos con un estudio de caso, un trabajo donde se analiza la huelga ferroviaria de 1912 (Suriano 1991). También encontramos menciones a la huelga de los marítimos, acontecida en aquella época, en investigaciones más amplias sobre el sector (Adelman 1993; Caruso 2016). Estos años fueron analizados especialmente desde la perspectiva del sistema político, por la novedad que representó la Ley Sáenz Peña. Es decir, fueron más estudiados “desde arriba" que "desde abajo" (Ansaldi 2012; Botana 1985; Castro 2012; Garguin 1999; Justo López 2005). 
El período comprendido entre el Centenario y la primera presidencia de Yrigoyen representa una fase de transición en varios sentidos. A nivel de la estructura económica se estaba llegando al límite de la frontera agrícola, abriendo las puertas a una crisis estructural (Belini y Korol 2012). El año 1913, específicamente, marca el inicio de una larga depresión económica que se extendió hasta 1917 (Palacio 2000). Su consecuencia más inmediata para el movimiento obrero fue el incremento de la desocupación. En el plano político son los años de transición entre el régimen oligárquico y un sistema de democracia ampliada (Ansaldi 2000). En el terreno del movimiento obrero se estaba produciendo también un cambio fundamental, son los años de declive del anarquismo y del fortalecimiento de la corriente sindicalista. Por lo tanto, el análisis de la huelga general, que realizamos en el presente artículo, se inscribe en un contexto histórico de transición en diversos sentidos; el paro nacional, sus debates y sus consecuencias expresan este proceso de transición multidimensional.

Según las estadísticas sobre conflictividad gremial elaboradas por el DNT para el ámbito de la Capital Federal, el año 1913 muestra un descenso en el número de huelgas y de huelguistas. Sin embargo, en el transcurso de nuestra investigación, hemos encontrado que en ese mismo año ocurrieron grandes protestas obreras fuera de la Capital Federal, en las provincias de Santa Fe y Buenos Aires. En abril, los guardas y conductores de tranvías eléctricos de la ciudad de Rosario se declararon en huelga, la situación derivó rápidamente en una huelga general en aquella importante urbe santafecina. En agosto estalló un conflicto gremial en la localidad bonaerense de Los Pinos que fue acompañada por una huelga general solidaria de los trabajadores de la vecina ciudad de Balcarce. En septiembre, la conflictividad social se extendió a las localidades de Tandil, Berazategui, Los Pinos (Balcarce) y Arroyo Pareja (Punta Alta); este fue el momento culminante de la protesta social. En estos cuatro casos la represión estatal contra la protesta obrera fue desmedida y brutal. 


\section{Gráfico 1.}

Huelgas y huelguistas

1907 - 1912

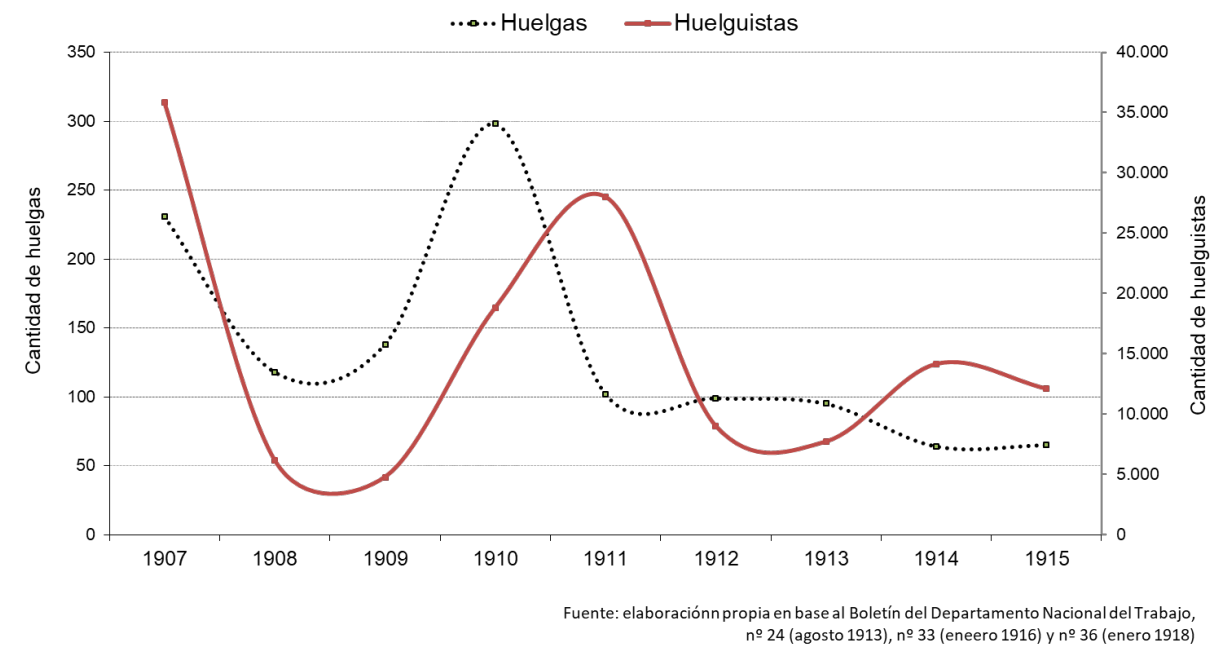

Cuando las noticias llegaron a la Capital Federal, las centrales obreras deliberaron sobre la actitud que debían adoptar. Tanto la FORA como la CORA barajaron la posibilidad de declarar la huelga general. En ambos casos se percibe una enorme cautela, tratando de evitar medidas extremas, se intentó llamar la atención del gobierno por otras vías. Como veremos más adelante, las centrales obreras van a dilatar y postergar hasta el extremo la decisión de convocar a la huelga general, esperando un gesto del gobierno que permita desactivar el conflicto. Sin embargo, la cerrazón de las autoridades ante las demandas del movimiento obrero va a empujar a la FORA, a pesar de sus vacilaciones, a declarar la huelga general. La CORA se va a oponer, considerando que no estaban dadas las condiciones para realizar una medida de tamaña envergadura. Estas desavenencias van a tener importantes consecuencias para el futuro del movimiento obrero. En los siguientes apartados reseñamos cada uno de estos grandes conflictos acontecidos en el año 1913, luego abordamos los debates sobre la huelga general que tuvieron lugar dentro de las centrales obreras y finalmente planteamos las consecuencias que tuvo para el movimiento obrero la malograda huelga general. 


\section{La huelga general rosarina}

En la ciudad de Rosario, en abril de 1913, los guardas y conductores de tranvías eléctricos se declararon en huelga. Rápidamente se propagó a otros gremios, hasta convertirse en general. El conflicto se originó por una decisión de la empresa, que resolvió disminuir en 26 los coches que prestaban servicios en aquella localidad ${ }^{3}$. La medida dejaba cesantes a 108 trabajadores ${ }^{4}$. Inmediatamente, los obreros exigieron a la empresa que restableciera íntegramente el servicio y reincorporara a todo el personal afectado. Ante la negativa patronal, los motoristas y mayorales se declararon en huelga desde el lunes 21 de abril. Los empleados de tranvías gestionaron la adhesión de los cocheros y del personal de maestranza de la municipalidad". "Como se anunció, los cocheros y obreros municipales se declararon en huelga como acto de solidaridad, plegándose todos al movimiento" " Cada hora que pasaba el conflicto adquiría mayores dimensiones. "La huelga [...] se extiende a otros gremios, con perspectivas de convertirse en huelga general" " La Federación Obrera Local de Rosario (FOLR) convocó a una asamblea para el viernes por la noche. Por su parte, la Federación Obrera Ferroviaria de aquella localidad, dirigida por los sindicalistas, convocó a una asamblea para el sábado. Finalmente, la FOLR declaró la huelga general desde el sábado 26, lo mismo hizo la FOF. Además, se adhirieron los obreros gráficos, cigarreros y carreros, entre otros. En vistas del agravamiento de la situación, el gobernador ${ }^{8}$ solicitó al ministro del interior el envío de tropas de línea. Al mismo tiempo, propuso que una comisión arbitral resolviera el conflicto. Después de intensas negociaciones, los huelguistas aceptaron la propuesta ${ }^{9}$. El tribunal de arbitraje estaría compuesto por dos representantes de cada parte y un tercero

\footnotetext{
3 “Circulación de tranvías”, La Nación, XLIII, 15036, 17/4/1913, p. 10.

4 "Rosario: huelga de conductores de tranvías", La Nación, XLIII, 15038, 19/4/1913, p. 9.

5 "La huelga del personal de tranvías", La Nación, XLIII, 15040, 21/4/1913, p. 10.

6 “La Vanguardia en Rosario", La Vanguardia, XX, 2183, 25/4/1913, p. 1.

7 “Rosario: el movimiento huelguista", La Nación, XLIII, 15044, 25/4/1913, p. 9.

${ }^{8}$ El gobernador de Santa Fe era el radical Manuel J. Menchaca, fue el primer gobernador elegido aplicando la Ley Sáenz Peña.

9 “La huelga del Rosario", La Nación, XLIII, 15047, 28/4/1913, p. 8.
} 
nombrado de común acuerdo. La empresa de tranvías designó al ingeniero Mauricio Book y a Pedro Narc, y los huelguistas a Narciso A. Gnoato ${ }^{10}$ (socialista) y a Constancio Panizza (anarquista). El conflicto parecía encarrilarse hacia una solución negociada. Sin embargo, el lunes 28, "los árbitros nombrados por los huelguistas y la empresa de tranvías no consiguieron entenderse y dieron por terminadas sus gestiones" ${ }^{11}$. Las partes en conflicto volvieron a distanciarse. Carlos Balzán, delegado de la FORA, fue detenido en el despacho del gobernador, donde se encontraba negociando en representación de los huelguistas. En ese contexto, el Centro Socialista de la ciudad de Rosario lanzó un manifiesto aconsejando calma y prudencia a los huelguistas. "La clase trabajadora [...] debe mantenerse inalterablemente dentro de la legalidad y del orden [...] y recibir con desagrado las actos y manifestaciones que no observan este temperamento". Ante el fracaso de las negociaciones, los obreros tranviarios y municipales solicitaron telegráficamente la presencia "urgentísima" de Juan B. Justo ${ }^{12}$. Los diputados Justo y Bravo viajaron esa misma noche para Rosario y arribaron a la ciudad al día siguiente. Mantuvieron reiteradas entrevistas con el comité de huelga y con el mismo gobernador, sin arribar a ningún acuerdo. Ese mismo día, el martes 29, se reunió el Consejo Confederal de la CORA, organismo que "resolvió declarar su decidida solidaridad con los trabajadores de aquella ciudad y formular su enérgica protesta contra [...] el gobierno nacional y el provincial, que tienden, dice, a ahogar el movimiento"13. Advertía que en caso de agravarse la situación, la CORA podía profundizar las medidas de protesta. El Consejo Federal de la FORA también se reunió de urgencia y emitió un comunicado, donde alertaba a los trabajadores y les aconsejaba que debían estar "preparados para todo lo que pueda ocurrir"14. La CORA y la FORA tomaban cartas en el asunto, advertían sobre una eventual profundización del conflicto y no descartaban medidas de solidaridad. Sin embargo, en ese preciso momento, la

\footnotetext{
${ }^{10}$ Narciso A. Gnoato era miembro del directorio de la cooperativa rosarina "El Porvenir Obrero", ver "La Vanguardia en Rosario", La Vanguardia, XX, 2136, 1/3/1913, p. 2.

11 “La huelga del Rosario", La Nación, XLIII, 15048, 29/4/1913, p. 10.

12 "La huelga general en el Rosario", La Vanguardia, XX, 2186, 29/4/1913, p. 1.

13 "La Confederación obrera", La Nación, XLIII, 15049, 30/4/1913, p. 10.

14 "Huelga General de Rosario", La Protesta, XVII, 1981, 1/5/1913, p. 4.
} 
intervención de los diputados socialistas, Justo y Bravo, quebró la unidad obrera.

El comité de huelga general, encabezado por la FOLR, "exigió de los obreros tranviarios la eliminación de los diputados Justo y Bravo en sus gestiones cerca de los huelguistas". En caso contrario, el comité daría por terminada la huelga general en la ciudad de Rosario. Los conductores y guardas de tranvías rechazaron el ultimátum. En consecuencia, el comité resolvió dar por terminada la huelga general y lanzó un manifiesto invitando a los gremios a reanudar el trabajo. El comunicado de la FOLR, fechado el miércoles 30, un día después del arribo de Justo y Bravo a la ciudad, decía que la intromisión de los diputados socialistas rompía el pacto solidario, en el cual estaba comprometida toda la clase obrera de Rosario. Por ese motivo, la decisión de los tranviarios era considerada una traición "cobarde y ruin". La FOLR consideraba inaceptable que los obreros se rebajen "ante dos políticos que desconocen el comité de huelga general”. En consecuencia, resolvía "dar por terminada la huelga general". El comunicado llevaba la firma de Esteban Verga, su secretario general ${ }^{15}$. La ruptura del frente obrero condujo a la derrota de los empleados de tranvías, quienes dieron por concluida la huelga, sin que hayan conseguido la reincorporación de sus compañeros despedidos ${ }^{16}$.

Los sindicalistas analizaron extensamente el conflicto de los tranviarios rosarinos. Manifestaron que lo sucedido confirmaba su estrategia política y desacreditaba la de sus adversarios. "Hechos nuevos vienen a confirmar los principios del sindicalismo revolucionario". En referencia a la intervención de los diputados socialistas, ratificaron sus posturas contrarias a la intromisión de líderes políticos, considerados ajenos al movimiento obrero, en las luchas gremiales. "El proletariado no puede contar ni confiar más que en sus propias fuerzas congregadas en sus sindicatos". En relación al origen del conflicto, los sindicalistas señalaron que la compañía de transportes pretendía terminar con el flamante sindicato. "La empresa de tranvías

15 “La huelga general de Rosario”, La Protesta, XVII, 1982, 4/5/1913, p. 4.

16 Sobre sus gestiones en Rosario, Juan B. Justo declaró: "Nosotros fuimos al Rosario llamados por los empleados de tranvías. Sabíamos que nuestras negociaciones fracasarían. Sin embargo, tentamos. Pero fue inútil", en "La huelga rosarina: reportaje al doctor Justo", La Vanguardia, XX, 21889, 3/5/1913, p. 1. 
eléctricos de esa ciudad quería dar un golpe contra el sindicato, de fundación reciente". Detrás de la reestructuración del servicio, denunciaron los sindicalistas, se escondían motivos antisindicales. "Se quería destruir el sindicato de los empleados a toda costa". El acompañamiento activo del resto de los trabajadores fue destacado positivamente por los sindicalistas. "La solidaridad de los demás trabajadores se manifestó bien pronto. Primero los empleados municipales, después los conductores de vehículos, y, llevados por las circunstancias, todos los demás gremios después". También elogiaron las acciones violentas que desplegaron los huelguistas: "los tranvías que quiso poner en circulación la empresa, a instancia de la policía, conducidos por inspectores y mecánicos, fueron apedreados primero y después perseguidos a tiros". La infraestructura de la ciudad también sufrió diversas averías. "El alumbrado público en la mayor parte de la ciudad, no pudo efectuarse por haber quedado destrozada toda la instalación, como ser focos, faroles, hilos, etc.”. Los sindicalistas apuntaron contra el arbitraje y la intervención de los diputados socialistas en el conflicto. Subrayaron la ineficacia de ambos recursos:

Lo que ha demostrado con el resultado desastroso del movimiento es la inutilidad del arbitraje y su impotencia para dar solución a una lucha. Igualmente queda demostrada la inutilidad de la intervención de los diputados socialistas en las huelgas, pues ni con su autoridad ni con su prestigio como tales logran nunca hacer respetar las pretensiones, siempre justas, de los obreros. ${ }^{17}$

Los sindicalistas repetían sus postulados originales, oponiéndose a todo tipo de arbitraje o intromisión de los políticos en el movimiento obrero. También señalaron otro de los puntos débiles del conflicto. La huelga quedó circunscripta a la ciudad de Rosario. Los trabajadores de Capital Federal y del resto del país no prestaron su apoyo solidario. La responsabilidad se la adjudicaron a la división del movimiento obrero y en última instancia a los anarquistas, considerados culpables de aquella situación. "Buenos Aires nada hizo porque nada podía hacer seriamente. [...] A cualquier declaración de huelga general, no hubiesen respondido en la capital, ni tres mil obreros.

17 "La huelga general en Rosario", La Acción Obrera, VIII, 280, 3/5/1913, p. 1. 
Con la división existente, el desconcierto es completo" ${ }^{18}$. En definitiva, las críticas de los sindicalistas estaban dirigidas a los mecanismos de mediación (estatales o partidarios) y a la fractura del movimiento obrero, que imposibilitó una respuesta unificada de parte de los trabajadores ${ }^{19}$.

\section{Conflictos obreros y represión en la provincia de Buenos Aires}

\section{III.1. Los picapedreros de Tandil}

A diferencia de lo que ocurría en Santa Fe, la provincia de Buenos Aires estaba aún administrada por los conservadores. En 1913, fue un año excepcional, en el poder ejecutivo provincial se sucedieron cuatro gobernadores, dos de ellos murieron en ejercicio del cargo ${ }^{20}$. Ese año, en la provincia de Buenos Aires, estallaron varias protestas obreras; cuatro conflictos asumieron gran envergadura y repercutieron con fuerza en la Capital Federal. En dos de ellos, los militantes sindicalistas ocuparon un rol protagónico, en los otros dos la conducción estuvo en manos del anarquismo.

En septiembre de 1913, los obreros picapedreros de Tandil se declararon en huelga. El sindicato que los agrupaba, la Unión Obrera de las Canteras (UOC), fue fundado el 6 de octubre 1906. En sus orígenes, los anarquistas jugaron un rol destacado, pero su hegemonía fue pronto disputada por el sindicalismo revolucionario. Hacia 1911, su influencia era claramente visible en el estatuto del sindicato aprobado aquel año (Nario 1997). En sus

\footnotetext{
18 “Ecos de la huelga rosarina”, La Acción Obrera, VIII, 281, 10/5/1913, p. 1.

19 “La lucha colosal del Rosario es una lección, y nada más rica y todo, pero nada más que una lección. Nos dice ella claramente que el proletariado no ha de confiarse su suerte ni a terceros, ni a mediadores de ninguna clase, sean diputados u otros personajes. Nos dice que frente a una colación burguesa constituida por autoridades, el estado y el ejército, solo la acción unánime y simultánea de la clase obrera organizada del país, pueden surtir efecto en un sentido victorioso para los obreros comprometidos en la contienda", "Ecos de la huelga rosarina", La Acción Obrera, VIII, 281, 10/5/1913, p. 1 .

${ }^{20}$ Los gobernadores, en orden cronológico, fueron los siguientes: Ezequiel de la Serna, Eduardo Arana, Juan Manuel Ortiz de Rosas y Luis García.
} 
primeros años de existencia, el gremio de picapedreros desplegó una gran capacidad de combate. La medida de fuerza más recordada, llevada a cabo por el sindicato, es la denominada «huelga grande», que se prolongó por once meses, entre octubre de 1908 y septiembre de 1909. Este conflicto fue muy importante, no sólo por su extensión, sino porque concluyó en un gran triunfo para los trabajadores, consiguiendo mejoras significativas en su salario y condiciones de trabajo, consolidando el poderío de la organización gremial. En esta huelga, como en otras posteriores, la protesta de los picapedreros comprendió grados diversos de violencia, incluyendo balaceras y muertos. Estos elementos hacían de Tandil un caso particularmente sensible para las autoridades locales, provinciales y nacionales. Por lo tanto, el conflicto desencadenado en 1913 y la respuesta de las autoridades policiales, hay que enmarcarlas dentro de esta corta pero intensa tradición combativa del sindicato canterista.

El conflicto se originó en el cerro San Luis, cuando la empresa Vieyra y Cía. quiso contratar a 60 trabajadores que no estaban agremiados. Los obreros bajaron de las sierras para impedir el ingreso de los «crumiros». La policía intervino violentamente, comenzó a disparar, tratando de dispersar a los manifestantes. Los picapedreros resistieron, "se distribuyeron convenientemente poniéndose en reparo tras las peñas, y contestaron al fuego con el fuego" ${ }^{21}$. La balacera culminó con varios heridos. La policía detuvo a varios obreros, "acusándolos de haber atacado a los trabajadores importados por los patrones”. El conflicto se generalizó, "los obreros de las demás canteras acordaron la huelga general del gremio"22. Enterado de los sucesos, el jefe de policía de la provincia, "envió al Tandil un refuerzo de 50 hombres, al mando del comisario Laffite"23. Las fuerzas represivas coartaron severamente las libertades públicas. "El derecho de reunión les ha sido absolutamente negado a los canteristas" 24 . Los trabajadores en huelga solicitaron a la CORA que envíe una delegación. Al día siguiente, los sindicalistas Lotito y Montesano partieron para la ciudad de Tandil, con el

\footnotetext{
21 "Los sucesos del Tandil", La Acción Obrera, IX, 302, 11/10/1913, p. 1.

22 "El conflicto del Tandil", La Vanguardia, XX, 2318, 2/10/1913, p. 3.

23 "Las huelgas en la provincia de Buenos Aires: el caso del Tandil", La Nación, XLIII, 15201, 1/10/1913, p. 12.

24 "Huelga de Picapedreros en las canteras de Tandil", La Protesta, XVIII, 2059, 4/10/1913, p. 3.
} 
propósito de ayudar a los huelguistas. El conflicto se prolongó por varios meses. Aquí nos interesa rescatar las siguientes particularidades. En primer lugar, la patronal se propuso quebrar o debilitar la organización gremial, la poderosa Unión Obrera de las Canteras. En segundo lugar, la policía intervino con mucha violencia, provocando que el conflicto se agudice rápidamente. Cercenó libertades públicas y detuvo a varios trabajadores. En tercer lugar, la huelga asumió grandes dimensiones, abarcó a más de 3.000 trabajadores. En cuarto lugar, los sindicalistas ocuparon un rol protagónico, los dirigentes de la organización gremial pertenecían a la corriente y los delegados de la CORA tuvieron un papel decisivo en el conflicto.

\section{III.2. La huelga en la cristalería Rigolleau}

En septiembre de 1913, en la ciudad de Berazategui, se declararon en huelga los 1.200 obreros de la cristalería Rigolleau. El mes anterior había estallado un conflicto similar, los obreros denunciaban el maltrato sistemático al que eran sometidos por parte de la empresa y exigían que se terminen las multas y descuentos aplicados por los capataces ${ }^{25}$, en esa ocasión se llegó a un acuerdo pero la empresa no lo respetó. Con el propósito de ahogar el creciente malestar obrero, la policía decidió instalarse en el interior de la fábrica. Entonces, la paciencia de los trabajadores se agotó. En una asamblea realizada el domingo 7 de septiembre, resolvieron retomar las medidas de fuerza ${ }^{26}$, paralizando las actividades en todas las secciones de la empresa $^{27}$. Una delegación de la FORA viajó a Berazategui para respaldar a los trabajadores en conflicto. En este caso, fueron los militantes anarquistas los que ocuparon un papel central. La huelga se extendió por varios meses, en el transcurso de la misma se sucedieron innumerables atropellos policiales. El día 11 de septiembre, el corresponsal de $\mathrm{La}$

25 "De Berazategui: 1200 vidrieros en huelga", La Vanguardia, XX, 2277, 15/8/1913, p. 3.

26 "En Berazategui: nueva declaración de huelga", La Protesta, XVIII, 2036, 7/9/1913, p. 5.

${ }^{27}$ El pliego de reivindicaciones era el siguiente: “ $1^{\circ}$ Despido de los jefes José C. Sabaté y Maubert, $2^{\circ}$ Exacto cumplimiento de las bases de arreglo del último conflicto, $3^{\circ}$ Retiro de la policía de las Cristalerías Rigolleau, $4^{\circ}$ Que nadie sea despedido por el actual movimiento", en "De Berazategui", La Vanguardia, XX, 2298, 9/9/2013, p. 3. 
Vanguardia informaba: "Otra vez la policía vuelve a entrar en acción encarcelando a [...] obreros y obstaculizando el derecho de reunión [...] detuvo en la calle a un grupo de 18 personas. [...] La policía ha prohibido las reuniones de los huelguistas" 28 . Dos representantes de la FORA viajaron a La Plata para entrevistarse con el jefe de policía de la provincia para reclamarle por el derecho de reunión. La represión continuó en aumento. El lunes 29 de septiembre, las fuerzas policiales disolvieron a balazos una asamblea obrera, varios huelguistas resultaron heridos y otros tantos fueron $\operatorname{arrestados}^{29}$. Los sindicalistas denunciaron la represión policial. "Las prisiones se efectúan diariamente. Las prohibiciones de reuniones, los ataques a mano armada, a tiros y machetazos, son cosas de todos los momentos en este pueblo". Pero además, señalaron los vínculos de las fuerzas represivas con los empresarios. "Tal es la subordinación policial al burgués, que la comisaría está establecida en la misma fábrica. Los policías son verdaderos peones de ella"30. El conflicto en Berazategui alcanzó su clímax cuando los obreros de las canteras de Tandil se declaraban en huelga. En ambos casos, la represión policial fue brutal, disolviendo asambleas, hiriendo a trabajadores y encarcelando a gran cantidad de huelguistas.

\section{III.3. Los trabajadores canteristas de Los Pinos}

En la localidad de Los Pinos, ubicada a $15 \mathrm{~km}$ de la ciudad bonaerense de Balcarce, tuvo lugar otro importante conflicto laboral. En las canteras de aquel poblado, trabajaban cerca de 400 obreros. E1 9 de julio, como producto de una gira de propaganda efectuada por la CORA, se creó el «Sindicato de Trabajadores de las Canteras de Los Pinos», adherido a la central obrera sindicalista. En la fundación, participaron algunos experimentados activistas del gremio de picapedreros de Tandil ${ }^{31}$. Muchos obreros

\footnotetext{
28 "De Berazategui: la huelga en las cristalerías Rigolleau", La Vanguardia, XX, 2301, 12/9/1913, p. 4.

29 “La huelga de Berazategui: choque sangriento", La Nación, XLIII, 15200, 30/9/1913, p. 17.

30 "Huelga de Berazategui", La Acción Obrera, IX, 301, 4/10/1911, p. 2.

31 “La organización obrera en Los Pinos”, La Acción Obrera, IX, 291, 26/7/1913, p. 1. La noticia de la fundación del sindicato también aparece registrada en las actas de la CORA. En la sesión del Consejo Confederal, efectuada el 27/7/1913, entre las notas
} 
trabajaban en ambas localidades, siendo familiares, amigos, conocidos, etc. Estos vínculos permitieron la circulación de experiencias y conocimientos diversos, sobre las actividades políticas y sindicales, entre los empleados de las canteras, fortaleciendo su identidad colectiva. La decisión de los obreros de organizarse disgustó a los empresarios. Pocas semanas después, una de las compañías despidió a un trabajador. La medida constituía una provocación y una represalia por la conformación del sindicato. En solidaridad, sus compañeros decidieron abandonar el trabajo, exigiendo su inmediata reincorporación. Apenas conocida la noticia, los funcionarios policiales intimidaron a los trabajadores para que reanuden sus labores. "Desde el primer momento la autoridad amenazó a los huelguistas, llegando a decirles que si el lunes no habían vuelto al trabajo, que los iba a meter preso a todos". Los obreros más experimentados infundieron confianza entre los más jóvenes. "Entre estos obreros hay algunos luchadores de otras contiendas, avezados a esta clase de conflictos, que inspiran valor a los nuevos" 32 . Inmediatamente, la CORA decidió enviar a Félix Godoy al lugar de los hechos, para acompañar a los obreros en lucha. El 4 de agosto, la policía de Balcarce arremetió contra los huelguistas, "mientras unos apuntaban sus armas otros cargaban a caballo y la emprendían a rebencazos

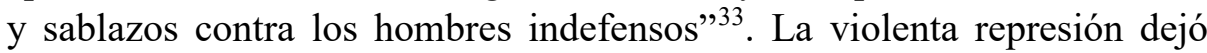
como saldo varios obreros heridos y detenidos ${ }^{34}$. El atropello de las fuerzas policiales no consiguió quebrantar el espíritu de lucha de los trabajadores canteristas. Por el contrario, exaltó aún más los ánimos. Finalmente, la patronal cedió y dispuso la reincorporación del trabajador despedido, motivo que había originado el conflicto ${ }^{35}$. El miércoles 6 de agosto los obreros retornaron a sus labores ${ }^{36}$.

Sin embargo, los empresarios y las autoridades no se quedaron conformes con la resolución de la huelga. El día 25 de agosto, en horas de

recibidas se menciona la siguiente: "Los Pinos 15 [julio] comunicando haberse organizado los obreros picapedreros adherida a la Confederación”, Libro de Actas de la CORA, 25/7/1913, p. 256.

32 "Huelga en Los Pinos", La Acción Obrera, IX, 292, 2/8/1913, p. 1.

33 "Vida Obrera", La Acción Obrera, IX, 293, 9/8/1913, p. 1.

34 "De Los Pinos", La Vanguardia, XX, 2268, 5/8/1913, p. 2.

35 "Vida Obrera", La Acción Obrera, IX, 294, 16/8/1913, p. 1.

36 "De Balcarce: huelga resuelta", La Vanguardia, XX, 2270, 7/8/1913, p. 3. 
la madrugada, sin previo aviso ni orden judicial, la policía asaltó las casas y el galpón donde habitaban los trabajadores ${ }^{37}$. "Atropellando violentamente el hogar de tranquilos trabajadores, las puertas [...] eran derrumbadas a fuerza de golpe y machete". Los agentes provocaron destrozos en sus viviendas y saquearon los bienes personales de los obreros. El local donde funcionaba el sindicato también fue allanado violentamente, "libros, sellos, recibos y demás útiles, fueron secuestrados por los policianos" ${ }^{38}$. Además de saquear y destrozar los bienes privados y comunes de los trabajadores, la policía arrestó a 12 obreros canteristas y expulsó de la ciudad a "los elementos más activos y rebeldes" 39 . Los sindicalistas denunciaron el vínculo entre las fuerzas represivas y el capital. "La policía, perra guardiana de los intereses burgueses, bajo la inspiración de éstos, con el fin de quebrar la organización llevó a cabo este malón" 40 . En esas circunstancias, aconsejaron la autodefensa armada de los trabajadores. "Los obreros tienen el derecho de repeler en cualquier forma un asalto policial [...] Si hubiese sido repelida a tiros, ninguna responsabilidad legal podía recaer sobre los asaltados. ¡Es lástima que no lo hayan hecho!" 41.

Ante la gravedad de los acontecimientos, la CORA se reunió de urgencia y decidió volver a enviar a Félix Godoy, como delegado de la central obrera, a la localidad de Los Pinos ${ }^{42}$. La represión golpeó duramente al novel sindicato, sus miembros quedaron desarticulados y comenzaron a desmoralizarse. Una vez arribado a la ciudad, Godoy emprendió la tarea de reunir nuevamente al gremio y levantar el ánimo de los obreros. Las actividades desplegadas por el delegado de la CORA rindieron sus frutos. El domingo 31 de agosto, "los obreros, en su totalidad, votaron la huelga de protesta, exigiendo la libertad de los compañeros detenidos y la readmisión de todo el personal que había sido expulsado" ${ }^{33}$. Ese mismo día, los trabajadores de la vecina ciudad de Balcarce se sumaron a la protesta, declararon la huelga general en solidaridad con los obreros de Los Pinos.

\footnotetext{
37 “En Los Pinos", La Vanguardia, XX, 2287, 27/8/1913, p. 4.

38 "Los obreros canteristas de Los Pinos", La Vanguardia, XX, 2290, 30/8/1913, p. 2.

39 "El vandalismo policial en Los Pinos, La Acción Obrera, IX, 297, 6/9/1913, p. 1.

40 "Vida Obrera", La Acción Obrera, IX, 296, 30/8/1913, p. 1.

41 "El vandalismo policial en Los Pinos", La Acción Obrera, IX, 297, 6/9/1913, p. 1.

42 "De Balcarce", La Vanguardia, XX, 2289, 29/8/1913, p. 3.

43 “El vandalismo policial en Los Pinos", La Acción Obrera, IX, 297, 6/9/1913, p. 1.
} 
Entonces, Godoy envió un telegrama a Buenos Aires solicitando que la CORA envíe un delegado más. El Consejo Confederal, reunido el $1^{\circ}$ de septiembre, designó a Sebastián Marotta para esa misión ${ }^{44}$. La presencia de los delegados de la central obrera sindicalistas seguramente irritó a los militantes anarquistas de la región. A su vez, la FORA también se solidarizó con los trabajadores en conflicto y decidió enviar Francisco López para cooperar con los huelguistas ${ }^{45}$. Esto nos muestra el entrecruzamiento de diversas tensiones, por un lado, tenemos el enfrentamiento entre los trabajadores canteristas con la policía y las patronales y al mismo tiempo se manifiestan disputas entre las principales corrientes políticas del movimiento obrero de la época, anarquistas y sindicalistas, dando cuenta de antagonismos transversales y de múltiples dimensiones ${ }^{46}$.

El primer día de la huelga, por la noche, se organizó una conferencia, donde hablaron los representantes de la CORA. "El movimiento de protesta de los obreros de Balcarce y Los Pinos es de grandes proporciones, pudiendo decirse que la huelga es general en las dos localidades"47. El miércoles 3, por la tarde, se llevó a cabo un acto en la plaza Libertad de Balcarce, donde acudieron cerca de 3.000 personas. Nuevamente, Marotta y Godoy hicieron uso de la palabra. Una vez finalizado el mitin, las columnas de manifestantes se dirigieron a la comisaría exigiendo la libertad de los presos. El viernes por la noche, los trabajadores de Balcarce, reunidos en asamblea, decidieron suspender "provisoriamente" la medida de fuerza, expresaron "el propósito de ir nuevamente a la huelga general, si el juez no

44 "El compañero Godoy manda un telegrama desde Balcarse pidiendo que el Consejo mande otro delegado en esa localidad, se acuerda que vaya el compañero S. Marotta", ver Libro de Actas de la CORA, 1/9/1913, p. 260. Ver también, "Viaje del secretario de la Confederación", La Vanguardia, XX, 2292, 2/9/1913, p. 2.

45 "La huelga de los canteristas de Los Pinos", La Protesta, XVIII, 2031, 2/9/1913, p. 5.

${ }^{46}$ Unos días más tarde, el periódico anarquista denunciaba que el delegado de la FORA fue rechazado con la excusa que esa institución "ha hecho campaña por dividir a los trabajadores", este episodio muestra las disputas existentes dentro del campo obrero y nos estaría indicando la supremacía sindicalista, pues, sus militantes consiguieron acallar al delegado anarquista, "El maridaje sindicalista-socialista", La Protesta, XVIII, 2035, 6/9/1913, p. 3. Ver también "Regreso del delegado de la FORA", La Protesta, XVIII, 2036, 7/9/1913, p. 5.

47 "Los obreros canteristas de Los Pinos", La Vanguardia, XX, 2293, 3/9/1913, p. 3. 
falla por la libertad de los presos" $" 48$. Por su parte, los obreros canteristas de Los Pinos continuaron con su lucha. La policía arremetió nuevamente contra los huelguistas, arrestando a 50 obreros canteristas. La medida de fuerza comenzó a deshilacharse. El núcleo más activo trató de resistir, pero no pudo revertir la situación. La huelga ingresó en un período de lenta agonía, del cual no pudo sobrevivir. En definitiva, los sindicalistas promovieron la formación del sindicato y fueron los principales sostenedores de la huelga. A su vez, los delegados de la CORA, Godoy y Marotta, ocuparon un lugar central en este conflicto. Como en los demás casos, la represión policial fue brutal y recurrente.

\section{III.4. La huelga en el puerto de Arroyo Pareja}

Los obreros de la compañía francesa, constructora del puerto de Arroyo Pareja, en Punta Alta, se declararon en huelga el lunes 22 de septiembre. El conflicto se originó por el despido de 33 trabajadores. La medida de fuerza abarcó a cerca de 1.300 empleados ${ }^{49}$. También en esta localidad, la policía persiguió y reprimió a los huelguistas. "Hoy la arbitrariedad rebalsa los límites de lo común: pasan de cuarenta el número de presos y otros están en vías de correr igual suerte". Los activistas eran vigilados permanentemente por las fuerzas de seguridad. "Policías de uniforme y sin él apestan el pueblo, husmean todos los lugares, [...] numerosos domicilios de los compañeros más activos están vigilados por la policía"50. Las asambleas obreras fueron prohibidas ${ }^{51}$. El diario anarquista La Protesta denunciaba esta situación: "la policía ha suspendido el derecho de reunión a los obreros en huelga" ${ }^{2}$. A pesar de las persecuciones policiales, los trabajadores mantuvieron la medida de fuerza. La FORA envió un delegado. El sábado

\footnotetext{
48 “La huelga general en Balcarce y Los Pinos”, La Acción Obrera, IX, 298, 13/9/1913, p. 1.

49 "Movimiento Obrero: Punta Alta", La Vanguardia, XX, 2316, 30/9/1913, p. 3. Ver también, "En Arroyo Parejas: huelga de los trabajadores del puerto", La Protesta, XVIII, 2050, 24/9/1913, p. 5.

50 "La huelga de Punta Alta", La Protesta, XVIII, 2053, 27/9/1913, p. 5.

51 "Movimiento Obrero", La Vanguardia, XX, 2316, 30/9/1913, p. 3.

52 "El derecho de reunión negado también en Punta Alta", La Protesta, XVIII, 2058, 3/10/1913, p. 3.
} 
11 de octubre se produjo un choque violento entre las fuerzas del orden y los obreros en huelga. Hubo varios heridos de ambos bandos. El agente José Amado falleció a consecuencia del enfrentamiento. El comité de huelga lanzó un manifiesto convocando al paro general. "Hay numerosos obreros detenidos con motivo de los sucesos ocurridos el sábado. [...] La policía ha sido aumentada y reforzada con conscriptos de la armada. También prohíbe toda clase de reuniones a los huelguistas" 53 . Un mes después de iniciada la huelga, las percusiones policiales quebraron la resistencia obrera, "ante la imposibilidad de continuar el movimiento se acordó la vuelta al trabajo" 54 . El trabajo se fue normalizando sin que los obreros obtuvieran sus demandas ${ }^{55}$. En este conflicto, también se evidencia la brutal represión ejercida por la policía en contra de los huelguistas. El cercenamiento de las libertades públicas y la prohibición del derecho de reunión, fueron componentes claves de esta huelga. Por último, mencionemos que los sindicalistas no tuvieron injerencia en este movimiento, aquí fueron los anarquistas los que ocuparon un rol protagónico.

\section{La huelga general, debates y consecuencias}

Estos cuatro conflictos, que hemos reseñado brevemente, tuvieron fuertes repercusiones en la Capital Federal. La violencia ejercida contra los huelguistas causó estupor e indignación en las organizaciones gremiales. Las centrales obreras se consideraron interpeladas por la feroz represión policial. Debatieron sobre las medidas de solidaridad que correspondía poner en marcha. Específicamente, exploraron la conveniencia de convocar a la huelga general. Días después de producirse la segunda represión a los trabajadores de Los Pinos, se reunió el Consejo de Delegados de la CORA.

\footnotetext{
53 “Movimiento Obrero", La Vanguardia, XX, 2328, 14/10/1914, p. 2. Ver también, "Huelga general en Punta Alta", La Protesta, XVIII, 2068, 15/10/1913, p. 1.

54 "De Punta Alta: la huelga de Arroyo Parejas, su terminación”, La Protesta, XVIII, 2079, 28/10/1913, p. 4.

${ }^{55}$ En los días previos, el diario anarquista anunciaba: "En los últimos días numerosos obreros han abandonado la zona de Punta Alta para ir hacia otras localidades en busca de trabajo, antes de rendirse a las exigencias de los explotadores", en "Huelga en Arroyo Parejas", La Protesta, XVIII, 2074, 22/10/1913, p. 3.
} 
El secretario provisorio, Lucas Tortorelli ${ }^{56}$, informó sobre los acontecimientos ocurridos en aquella localidad, "luego se pasa a discutirse lo que debe hacerse". Entre los asistentes, la opinión generalizada era pesimista, consideraban que las posibilidades de recurrir a la acción directa eran nulas. Cuomo sostuvo que "si bien la huelga en Balcarce sigue bien, en la capital no podría declararse porque iría a un fracaso". Loperena intervino en el mismo sentido: "en vista que no se puede hacer nada propone que se nombre un abogado para defender a los compañeros que se hallan presos". Finalmente, "después de un largo debate se acuerda nombrar un abogado" Los sindicalistas evaluaban que la debilidad de las organizaciones obreras impedía una respuesta más contundente a los atropellos policiales. La creciente conflictividad laboral en la provincia de Buenos Aires, acompañada de nuevas y más violentas represiones, reavivaron el debate sobre la huelga general. En la reunión de delegados efectuada por la FORA el 30 de septiembre, "se acordó autorizar al concejo [federal] para declarar la Huelga General cuando los sucesos así lo indicasen" ${ }^{58}$. Sin embargo, la FORA se va a mostrar reacia a convocar al paro nacional. El sábado 4 de octubre se reunieron, en paralelo, los delegados de ambas centrales obreras. Los representantes gremiales de la FORA deliberaron en el local de Montes de Oca 1672. El motivo de la convocatoria era tratar la situación creada por "la limitación denigrante del derecho de reunión y los procedimientos brutales, que cuestan tanta sangre y dolores proletarios, de las policías provinciales" $" 59$. La concurrencia fue numerosa. La asamblea decidió postergar la resolución, porque el Consejo Federal realizó gestiones ante el gobierno de la provincia de Buenos Aires y obtuvo la liberación de 130 presos. Entonces, "visto el giro que van tomando los acontecimientos", la FORA decidió "aplazar toda resolución definitiva [...] para poder apreciar [...] si se cumple con poner en libertad a todos los presos" ${ }^{60}$. De esta forma,

56 "Se acuerda que el compañero Tortorelli reemplace como secretario interino al camarada Marotta mientras dure la gira de propaganda", en Libro de Actas de la CORA, 22/8/1913, p. 259.

${ }^{57}$ Libro de Actas de la CORA, 5/9/1913, p. 261.

${ }^{58}$ Libro de Actas de la FORA, 30/9/1913, p. 6.

59 "Los grandes atropellos policiales en la provincia de Buenos Aires", La Protesta, XVIII, 2059, 4/10/1913, p. 1.

60 "La reunión de delegados de anoche", La Protesta, XVIII, 2060, 5/10/1913, p. 3. 
la FORA abrió un compás de espera para comprobar si el gobierno cumplía con su promesa y adoptar una decisión definitiva ${ }^{61}$.

Ese mismo día, la CORA efectuó una reunión extraordinaria de delegados. El secretario informó que el objeto de la convocatoria era tratar la declaración de huelga general que posiblemente realizaría la FORA. A continuación, leyó una nota enviada por Montesano, desde la ciudad de Tandil, pidiendo que la CORA proclame también la huelga general. Sin embargo, luego de un extenso debate, los delegados decidieron no declarar la huelga general. Además, acordaron publicar un manifiesto detallando los motivos de tal resolución ${ }^{62}$. El texto fue aprobado al día siguiente, luego de un acalorado debate ${ }^{63}$. En el mismo se decía que la CORA "cree que en estos momentos de percusión y de angustia, se hace indispensable una protesta vigorosa y enérgica contra el proceder salvaje de las autoridades". Sin embargo, "el distanciamiento, la división y los rencores que personas ambiciosas, ajenas al movimiento obrero y sin escrúpulos han venido sembrando entre el proletariado" 64 hacían inviable que el proletariado exteriorice su protesta. En otras palabras, la huelga general era necesaria en esas circunstancias, pero las divisiones generadas por los anarquistas impedían que se lleve a cabo con éxito. Entonces, ambas centrales obreras, por diversas razones, descartaron la posibilidad de convocar a una huelga general. La renuencia, a embarcarse en una lucha de tal envergadura, expresaba la situación de debilidad que estaba atravesando el movimiento obrero en ese período.

La FORA gestionó ante la policía un permiso para realizar "un mitin de protesta contra la policía de la provincia, por sus incalificables abusos y

${ }^{61}$ Los anarquistas se mostraron aliviados porque la decisión del gobierno le permitía a la FORA desactivar la convocatoria a la huelga general. "Después de esto, nos sentimos todos respirar, como librados de una gran opresión, porque sentíamos que la lucha iba a ser encarnizada y terrible y además estábamos convencidos de su fatalidad irremediable...". Aplaudieron a la FORA por el "mesuramiento enérgico de su procedimiento", "Las grandes huelgas de Berazategui y Punta Alta", La Protesta, XVIII, 2061, 7/10/1913, p. 1.

${ }^{62}$ Libro de Actas de la CORA, 4/10/1913, p. 264.

${ }^{63}$ Libro de Actas de la CORA, 5/10/1913, p. 265.

64 "Confederación Obrera Regional Argentina: al proletariado del país", El Obrero en Madera, VI, 62, octubre de 1913, p. 3. 
desmanes [...] hacia nuestros hermanos en huelga de Berazategui, Los Pinos, Punta Alta y Tandil" "65. El mitin debía efectuarse el domingo 19 de octubre $^{66}$. La autorización para realizar el acto le fue denegada. Entonces, la FORA restringió aún más sus demandas, desechó la posibilidad de efectuar un «mitin de protesta», en su lugar, decidió tramitar un nuevo permiso para realizar una "conferencia pública desistiendo del mitin callejero"67. A pesar de la reiterada moderación demostrada por la FORA, la policía rechazó nuevamente el permiso solicitado ${ }^{68}$. Recién entonces, acorralados por la cerrazón policial, los delegados de la FORA declararon la huelga general para los días viernes 24 y sábado 25 de octubre ${ }^{69}$.

La noticia del paro nacional, declarado por la central obrera ácrata, fue muy mal recibida por los dirigentes gremiales sindicalistas, desconocieron o impugnaron la resolución adoptada por la FORA. El secretario general del gremio de ebanistas, el principal bastión del sindicalismo en el movimiento obrero, declaró:

Mi opinión particular concuerda en un todo con el manifiesto publicado recientemente por la Confederación. Creo que por el estado actual de la organización -desgraciadamente dividida por culpa de los mismos anarquistas- y por la época de crisis porque se atraviesa, no es el momento oportuno para realizar movimientos de esa naturaleza. Las cosas no se hacen cuando se quiere, sino cuando se puede.

La explicación, formulada por Juan Cuomo, apuntaba directamente contra los mismos que estaban convocando a la medida de fuerza, los anarquistas. La debilidad de las organizaciones obreras, según su opinión, desaconsejaba la realización de una huelga general y esta situación era

${ }^{65}$ Libro de Actas de la FORA, 17/10/1913, p. 7.

66 "El mitin monstruo: para el domingo 19”, La Protesta, XVIII, 2064, 10/10/1913, p.

1. "La protesta más grandiosa contra la negación de los derechos de reunión y de huelga a los trabajadores", en "Gran mitin de protesta", La Protesta, XVIII, 2068, 15/10/1913, p. 1.

${ }^{67}$ Libro de Actas de la FORA, 17/10/1913, p. 7.

68 "El mitin de protesta", La Protesta, XVIII, 2071, 18/10/1913, p. 1.

${ }^{69}$ Libro de Actas de la FORA, 18/10/1913, p. 10 y ss. Ver también "La huelga general de protesta por dos días", La Protesta, XVIII, 2072, 19/10/1913, p. 1. 
responsabilidad de los militantes libertarios, que mantenían la división gremial. El secretario general de la Unión Chauffeurs, el sindicalista José Montesano, aseguró que su gremio no adhería a la huelga declarada por la FORA. El secretario general de la Federación Obrera Ferrocarrilera (FOF), Francisco Rosanova, dijo que su gremio no estaba en condiciones de ir a la huelga. "Estamos [...] en un período de organización, y todos nuestros esfuerzos y energías tienden a vencer la indiferencia que reina entre los ferroviarios". Por su parte, el secretario interino de la CORA, Lucas Tortorelli, manifestó: "Nuestro organismo, compuesto por 24 sociedades auténticas, alguna de las cuales cuentan con 4.000 asociados, no tiene noticia alguna de tal resolución, ni ha tomado hasta la fecha acuerdo alguno sobre el particular" ${ }^{70}$. El Consejo Confederal de la CORA ni siquiera trató el tema ${ }^{71}$. En definitiva, los principales referentes gremiales del sindicalismo revolucionario (Cuomo, Montesano, Rosanova y Tortorelli) rechazaron la medida de fuerza declarada por la FORA. Juan Perazzo, secretario general del gremio de Escultores en Madera, sindicato perteneciente a la CORA, también manifestó su desacuerdo con el paro resuelto por la central obrera anarquista ${ }^{72}$. Ángel Martínez, secretario general de la Sociedad de Herreros de Obra y Anexos, manifestó que la organización que presidía tampoco respaldaba la medida de fuerza. La Sociedad de Resistencia de Mecánicos y Anexos adoptó similar temperamento. "Reunido el gremio en asamblea general extraordinaria, resolvió por mayoría de votos no adherirse al paro general"73. La poderosa Federación Gráfica Bonaerense, también decidió que no adhería a la huelga general $^{74}$. La misma organización, aprobó una declaración donde manifestaba: "Que todas las sociedades obreras deberían esforzarse en llevar a sus asociados una propaganda intensa hacia la unificación de todos

\footnotetext{
70 "La huelga de la Federación”, La Vanguardia, XX, 2334, 21/10/1913, p. 2.

${ }^{71}$ Ver Libro de Actas de la CORA, pp. 265 y ss.

72 "Escultores en Madera", La Vanguardia, XX, 2337, 24/10/1913, p. 2.

73 "Sociedad de Resistencia Mecánicos y Anexos", La Vanguardia, XX, 2337, 24/10/1913, p. 2.

74 “La huelga general y la F.G.B.”, El Obrero Gráfico, V, 62, octubre y noviembre de 1913, p. 2.
} 
los gremios"75. Esta declaración, votada favorablemente por la asamblea de los gráficos, muestra la influencia del sindicalismo en ese gremio.

La FORA recibió el respaldo de una veintena de sindicatos, la mayoría eran gremios de escasa envergadura. La excepción fue la Federación Obrera Marítima, integrante de la central obrera anarquista, fue la organización más importante que apoyó la medida de fuerza ${ }^{76}$. La huelga general tuvo escaso acatamiento. Los mismos anarquistas anticiparon que quizás no sería "completa" sino "casi completa" ". Después reconocieron que la huelga no fue "tan general"78. Sin embargo, a pesar de sus reducidas dimensiones, los anarquistas sostuvieron que fue correcto convocar a la huelga general, porque era imprescindible protestar contra el Estado por los atropellos que estaba cometiendo, sin importar el grado de adhesión a la medida de fuerza. Por lo tanto, según los ácratas, el criterio correcto para realizar el balance de la huelga general radicaba en la justicia del reclamo y no en la capacidad de convocatoria ${ }^{79}$.

Según el DNT, apenas 16.000 trabajadores se plegaron al paro ${ }^{80}$. Es una cifra relativamente baja. En enero del año anterior, el número de huelguistas ascendía a casi el doble. Si vamos más atrás en el tiempo, la huelga general de enero de 1907 congregó a cerca de 150.000 obreros. Sin embargo, el número no es despreciable, expresaba, aunque de manera muy incipiente, cierta recuperación del movimiento obrero. La huelga afectó especialmente a los barrios de La Boca y Barracas ${ }^{81}$.

75 "Federación Gráfica Bonaerense: la asamblea de anoche", La Vanguardia, XX, 2338, 25/10/1913, p. 2.

${ }^{76}$ La decisión fue tomada a último momento, en una asamblea realizada la noche previa al inicio de la huelga general, ver "Movimiento Obrero", La Nación, XLIII, 15223, 23/10/1913, p. 10 y "Federación Obrera Marítima", La Protesta, XVIII, 2076, 24/10/1913, p. 3.

77 "La Huelga General y los fariseos de la acción obrera", La Protesta, XVIII, 2074, 22/10/1913, p. 1.

78 “La huelga general”, La Protesta, XVIII, 2078, 26/10/1913, p. 1.

79 “Después de la huelga", La Protesta, XVIII, 2079, 28/10/1913, p. 1.

${ }^{80}$ Boletín del Departamento Nacional del Trabajo, $\mathrm{n}^{\circ} 30,30 / 4 / 1915$

81 “Como en el día anterior, la huelga se circunscribió ayer a la ribera en la Boca y Barracas donde se notaba principalmente la falta de carros. En diversas barracas faltó parte del personal y en algunas fábricas y talleres de dichas localidades", en "La huelga: sus resultados", La Nación, XLIII, 15226, 26/10/1913, p. 13. 
E1 diario La Nación catalogó a la huelga como un fracaso ${ }^{82}$. Los socialistas expresaron opiniones similares. Celebraron que la medida de fuerza haya resultado un "ruidoso fracaso". La huelga general, "felizmente, no ha encontrado eco entre los trabajadores" ". Con satisfacción, resaltaron la escasa adhesión que concitó el paro. "La inmensa mayoría de los trabajadores organizados ha hecho caso omiso de la huelga general decretada por el consejo de la Federación, que pretendía erigirse en director de la clase obrera" ${ }^{\circ 4}$. Esta última frase desliza una velada acusación a la FORA, una segunda intención. Según esta interpretación, los ácratas habrían impulsado la huelga general, en soledad, para "erigirse en directores de la clase obrera". La central anarquista, todavía maltrecha por la represión del Centenario, pretendía recuperar el protagonismo que supo tener en el pasado. En las semanas previas, los socialistas denunciaron lo que consideraron "manejos turbios" en la conducción de la central obrera. La huelga general que se estaba preparando, decían, tenía como principal reivindicación la libertad de los obreros presos en Berazategui. La medida de fuerza, en aquella localidad, recordemos, era dirigida por la FORA. Los socialistas señalaban que en otros lugares de la provincia de Buenos Aires también había trabajadores presos. Sobre los dirigentes de la FORA, decían, "no se acuerdan para nada de los huelguistas encarcelados igualmente en otros puntos de la provincia -el Tandil y Los Pinos-, en condiciones más irritantes que [...] los vidrieros de Berazategui”" ${ }^{\prime 5}$. En los conflictos de Tandil y Los Pinos, como hemos visto, los militantes sindicalistas y la CORA tuvieron un papel protagónico. Los socialistas denunciaron la actitud partidista de la FORA hacia la huelga general, con la intención de "erigirse en directores de la clase obrera". En definitiva, el PS advierte que detrás del

82 "La huelga anunciada: fracaso del movimiento", La Nación, XLIII, 15225, 25/10/1913, p. 13.

83 "Charlatanismo peligroso", La Vanguardia, XX, 2338, 25/10/1913, p. 1.

84 "La tentativa de huelga general", La Vanguardia, XX, 2338, 25/10/1913, p. 2.

85 "Redacción: manejos turbios", La Vanguardia, XX, 2322, 7/10/1913, p. 1. Cuando la FORA finalmente decide convocar a un mitin de protesta y luego a la huelga general, denuncia los atropellos en todas las localidades, tanto los sucesos ocurridos en Berazategui y Punta Alta, donde los anarquistas tuvieron mayor influencia, como Tandil y Los Pinos, donde los sindicalistas ocuparon un papel preponderante, ver "Gran mitin de protesta”, La Protesta, XVIII, 2070, 17/10/1913, p. 1. 
llamado a la huelga general se esconden otros intereses. La medida de fuerza, en definitiva, era un arma de combate en la disputa por la dirección del movimiento obrero. Si la mayoría de los gremios adherían a la huelga general, es decir, si se encolumnaban detrás de la FORA, la central obrera anarquista se hubiese fortalecido. Ni los socialistas, ni los sindicalistas, querían que esto sucediese. Los sindicatos adheridos a la CORA juzgaron que si acataban la decisión de la FORA, quedaban relegados a un segundo lugar, subordinados a la central anarquista. La debilidad de las organizaciones gremiales y las querellas políticas, entre anarquistas y sindicalistas, impidieron que el movimiento obrero elaborara una manifestación de protesta masiva y unificada.

En sintonía con los líderes obreros de la CORA, los sindicalistas también afirmaron que naufragó el intento de realizar una huelga general, promovida por los ácratas y la FORA. "Los pretendidos manipuladores del movimiento obrero acaban de fracasar con el más ridículo de los fracasos”. Su discurso estaba impregnado de diatribas hacia los editores de La Protesta, periódico que era considerado la dirección política del anarquismo y por ende de la FORA. "Los trabajadores han desautorizado, en la última tentativa de «arrastre» a la huelga general, las evocaciones destartaladas de los mugrientos sicofantes de «La Protesta»". Los redactores del periódico libertario eran tildados de "canalla disolvente" y sobre la FORA afirmaban que pertenecía "sólo al recuerdo de las cosas que fueron". La exigua adhesión a la medida de fuerza, según los sindicalistas, era una demostración palpable del ocaso de la central anarquista, "un montón de ruinas, algo que al fin rodó a la huesa...". Ante el derrumbe de la FORA, "el elemento sano del proletariado", debía "reconcentrarse en una sólida organización". La militancia sindicalista consideró que la realidad confirmaba sus tesis principales, su enemigo principal se desmoronaba, el momento de la unidad -bajo su férula-, por fin, había llegado: "las calumnias se disipan, la traición se desenmascara y la obra de los sindicalistas surge deslumbrante en su lucha por la unidad de las fuerzas organizadas de los trabajadores". Presumían de su perseverancia y coherencia en favor de la unidad: "Estamos orgullosos y tenemos como un blasón de gloria la constancia por unir las fuerzas proletarias y el ataque sin tregua contra los 
que predican su división" ${ }^{86}$. Criticaban a los anarquistas y bregaban por la unidad obrero.

Los sindicalistas, al igual que los socialistas, conjeturaron que detrás de la convocatoria de la FORA se escondían segundas intenciones. Los anarquistas habrían convocada a la huelga, argumentaban, para recuperar su lugar de conducción en el movimiento obrero, al mismo tiempo, que pretendían empequeñecer a la CORA, sometiéndola al liderazgo de la FORA. "Si lograban [los anarquistas] un levantamiento del proletariado obedeciendo a su voz [...] al mismo tiempo que era el principio del éxito de sus logrerías, se apuntaban un tanto contra los sindicalistas". Por ese motivo, los sindicalistas le atribuyeron a la huelga general el carácter de un plebiscito. Si la huelga triunfaba, los anarquistas quedarían posicionados nuevamente como dirección del movimiento obrero, de lo contario, la CORA y los sindicalistas saldrían favorecidos. Desde este punto de vista, estaba en juego el prestigio y la capacidad de convocatoria de la FORA, que los anarquistas afirmaban que se mantenía intacta y los sindicalistas ponían en duda. Desde el Centenario habían transcurrido más de tres años, las relaciones de fuerzas al interior de movimiento obrero, ¿habían sufrido modificaciones? La huelga general, entendían los sindicalistas, iba a servir de termómetro. Según los sindicalistas, los ácratas creyeron que las huelgas en Tandil y Los Pinos obligarían a la CORA a declararse en favor de la huelga general. Por esa vía, los anarquistas llevarían a la central sindicalista "a caer de boca en el lazo astutamente tendido" por la FORA. Sin embargo, decían, la Confederación supo eludir la trampa que arteramente habrían urdido los anarquistas: "la prudente actitud de la C.O.R.A. resistiéndose a intervenir en este juego de fulleros, salvó de nuevo a la clase obrera" ${ }^{87}$.

El fracaso de la huelga general, aseveraban, representaba el golpe de gracia a las aspiraciones hegemónicas del anarquismo y habría demostrado la declinación irreversible de la FORA. En ese escenario, los sindicalistas y la CORA quedaban ubicados en una situación inmejorable para conquistar la dirección del movimiento obrero. Más aún, creyeron que estaban en condiciones de promover la unidad del movimiento obrero sin el concurso de los anarquistas. El 8 de agosto de 1913, el Consejo Confederal, había

\footnotetext{
86 "Sursum Corda", La Acción Obrera, IX, 305, 1/11/1913, p. 1.

87 “Tópicos actuales”, La Acción Obrera, IX, 307, 15/11/1913, p. 1.
} 
decido convocar al primer congreso de la CORA $^{88}$. Sin embargo, el 6 de noviembre, días después de finalizada la huelga general convocada por la FORA, la central obrera sindicalista resolvió ampliar la convocatoria e invitar también a las sociedades autónomas ${ }^{89}$. La CORA lanzó un manifiesto llamando a "una concentración de organizaciones obreras". El documento criticaba abiertamente a los militantes libertarios, desdeñaba "las concepciones estrechas de sus cerebros" y se burlaba de la insistencia en homenajear "una ridícula tradición", en referencia a la FORA. Estaban convencidos que podían avanzar hacia la unidad sin el consentimiento de los ácratas. "El hecho de que existan quienes pretenden perpetuar la división, no es causa para que las organizaciones deseosas de la unidad permanezcan desunidas". Es decir, ya no trataron de unificar a las dos centrales obreras. Desde ese momento, se despreocuparon de la opinión de la FORA y los anarquistas. La CORA fungiría de eje articulador de la unidad de movimiento obrero.

\section{Conclusiones}

La represión estatal y paraestatal, desencadenada contra el movimiento obrero en momentos de celebrarse el Centenario y la posterior ley de Defensa Social, golpeó duramente al conjunto de las organizaciones gremiales, pero apuntó especialmente contra la militancia ácrata. La FORA quedó prácticamente desarticulada, recomponiéndose recién dos años más $\operatorname{tarde}^{90}$. El periódico La Protesta recién pudo retornar a su formato diario en agosto de 1913 (Abad de Santillán 1927, 61). La debilidad de la FORA y el movimiento libertario fue aprovechada eficazmente por los sindicalistas, extendiendo su influencia en las organizaciones gremiales. En los conflictos obreros que hemos referido en este artículo se aprecia el creciente protagonismo que fue adquiriendo la corriente sindicalista en este período.

\footnotetext{
${ }^{88}$ Libro de Actas de la CORA, 8/8/1913, p. 258.

${ }^{89}$ Libro de Actas de la CORA, 6/11/1913, p. 258.

${ }^{90}$ La FORA permaneció descabezada por más de dos años, recién en octubre de 1912 pudo restablecer su Consejo Federal, en "F.O.R.A.: a las sociedades federadas", La Protesta, XVI, 1955, 3/11/1912, p. 2.
} 
De esta forma, el análisis que hemos desarrollado permite constatar la metamorfosis que se estaba produciendo dentro del movimiento obrero, entre la hegemonía ácrata y la hegemonía sindicalista, que será manifiesta en 1915 en el IX Congreso de la FORA.

La pesquisa que hemos presentado sobre la conflictividad obrera en las provincias de Santa Fe y Buenos Aires, aporta a la construcción de una mirada más amplia sobre el proceso huelguístico desarrollado en aquellos años, complementando las estadísticas del DNT, que se circunscriben exclusivamente al ámbito capitalino. Asimismo, de acuerdo a la investigación realizada, se puede apreciar que el endurecimiento de la represión policial, las restricciones al derecho de huelga y a la libertad de reunión, fue un proceso generalizado, que se extendió mucho más allá de la Capital Federal. En este sentido, se puede relativizar el proceso de ampliación democrática que estaba teniendo lugar en esos años, con la sanción de la Ley Sáenz Peña. Mientras se modernizaba el sistema político, se desarrollaba una férrea represión contra el movimiento obrero, sus organizaciones y expresiones políticas.

Junto con el cambio de orientación política que se estaba gestando en el movimiento obrero, entre una hegemonía anarquista en retroceso y un predominio creciente de la corriente sindicalista, también podemos apreciar una orientación más moderada en el conjunto de las organizaciones gremiales. Tanto la CORA sindicalistas como la FORA anarquista, negociaban con el estado abiertamente y en ambos casos fueron muy reacios a declarar la huelga general. La FORA intento por todos los medios evitar la confrontación con el Estado, sin embargo, la obstinación represiva del gobierno nacional, obligó a declarar la medida de fuerza, que era resistida por líderes obreros.

La huelga general de los días 24 y 25 de octubre de 1913, convocada en soledad por la FORA, y su escaso nivel de adhesión, renovó las pretensiones del sindicalismo revolucionario de postularse como dirección del movimiento obrero. La nueva relación de fuerzas, entre las principales corrientes, gestada después -y a consecuencia- del Centenario, alentó a los sindicalistas a postularse como líderes del proceso de unificación, sin esperar ni requerir el apoyo de la FORA. La huelga general de 1913 auspició el cambio de postura del sindicalismo revolucionario. Desde ese momento, se abrió el proceso que, luego de atravesar el Congreso de Concentración, 
culminó en el IX Congreso de la FORA, en el cual sus militantes alcanzaron la dirección de la principal central obrera de la época, coronando una década de esfuerzos destinados a tal fin.

\section{Referencias}

Abad de Santillán, Diego. 1927. "La Protesta: Su historia, sus diversas fases y su significación en el movimiento anarquista de América del Sur”. En Certamen Internacional de La Protesta, págs. 34-71. Buenos Aires: La Protesta.

Adelman, Jeremy. 1993. "State and Labour in Argentina: The Portworkers of Buenos Aires, 1910-21". Journal of Latin American Studies 25: 73102.

Andreassi, Alejandro. 1991. "Inmigración y huelga. Argentina, 19001920". Ayer 4: 117-145.

Ansaldi, Waldo. 2000. "La trunca transición del régimen oligárquico al régimen democrático". En Nueva Historia Argentina. Tomo VI: Democracia, conflicto social y renovación de ideas (1916-1930), págs. 15-57. Buenos Aires: Sudamericana.

- 2012. "«Que voten antes que nos boten»: La reforma electoral de 1912”. Estudios Sociales 43: 59-90.

Barrancos, Dora. 1990. Anarquismo, educación y costumbres en la Argentina: De principios de siglo. Buenos Aires: Contrapunto.

Belini, Claudio y Juan C. Korol. 2012. Historia económica de la Argentina en el siglo $X X$. Buenos Aires: Siglo XXI.

Bilsky, Edgardo. J. 1985. La FORA y el movimiento obrero (1900-1910), vols. 1 y 2. Buenos Aires: CEAL.

Boido, Jorge O. 2002. La primera huelga general en la República Argentina (1902). Sus características y significados, como expresión de la presencia de los obreros como clase en la lucha político-económica. Tesis de Licenciatura, Universidad Nacional de Luján.

Botana, Natalio R. 1985. El orden conservador: La política argentina entre 1880 y 1916. Buenos Aires: Hyspamérica. 
Caruso, Laura G. 2016. Embarcados. Los trabajadores maritimos y la vida a bordo: Sindicato, empresas y Estado en el puerto de Buenos Aires, 1889-1921. Buenos Aires: Imago Mundi.

Castro, Martín O. 2012. El ocaso de la república oligárquica: Poder, politica y reforma electoral, 1898-1912. Buenos Aires: Edhasa.

Ceruso, Diego. 2015. La izquierda en la fábrica la militancia obrera industrial en el lugar de trabajo, 1916-1943. Buenos Aires: Imago Mundi.

Costanzo, Gabriela A. 2007. "Lo inadmisible hecho historia. La Ley de Residencia de 1902 y la Ley de Defensa Social de 1910”. Sociedad 26: 1-13.

Franco, Marina. 2019. "El estado de excepción a comienzos del siglo XX: de la cuestión obrera a la cuestión nacional". Avances del Cesor XVI (20): 29-51.

Garguin, Enrique. (1999). "La marea roja. El triunfo socialista en las elecciones porteñas de 1913". Sociohistórica, 147-181.

. (2000). "Relaciones entre estado y sindicatos durante los gobiernos radicales, 1916-1930". En Panettieri, José (Ed.). Argentina: Trabajadores entre dos guerras, págs. 87-117. Eudeba.

Godio, Julio. 1972. El movimiento obrero y la cuestión nacional. Argentina: Inmigrantes asalariados y lucha de clases, 1880-1910. Buenos Aires: Erasmo.

Gordillo, Mónica. 1988. La Fraternidad en el movimiento obrero: Un modelo especial de relación (1916-1922). Buenos Aires: CEAL.

Horowitz, Joel. 2015. El radicalismo y el movimiento popular (1916-1930). Buenos Aires: Edhasa.

Iñigo Carrera, Nicolás. 2000. La estrategia de la clase obrera: 1936. Buenos Aires: PIMSA-La rosa blindada.

- 2013. "Aproximación al análisis del centenario como hito en la historia de la confrontación social argentina”. Pimsa Documentos y comunicaciones XIV: 69-116.

Justo López, Mario. 2005. De la república oligárquica a la república democrática. Estudio sobre la reforma política de Roque Sáenz Peña. Buenos Aires: Lumiere.

Korzeniewicz, Roberto. P. 1989. 'Labor Unrest in Argentina, 1887-1907”. Latin American Research Review 24 (3): 71-98. 
. (1995). "Labor Unrest in the World-Economy, 1870-1990". Review (Fernand Braudel Center) 18 (1): 105-116.

Lobato, Mirta Z., y Juan Suriano. 1990. “Argentina 1880-1930: Huelgas generales en un país agro-exportador". Latin American Labor News 2-3: 18-19.

Martínez Mazzola, Ricardo. 2011. "La neutralidad como problema y como solución. La política gremial del Partido Socialista después de la ruptura sindicalista". Identidades 1: 1-20.

Monserrat, María Alejandra. 2011. "Los trabajadores ferroviarios: Sus luchas y organizaciones sindicales en el contexto de la Argentina gobernada por el radicalismo (1916 - 1930)". Cuadernos del Ciesal 10: 97-118.

Nario, Hugo. 1997. Los Picapedreros. Tandil: Ediciones del Manantial.

Palacio, Juan M. 2000. "La antesala de lo peor: La economía argentina entre 1914 y 1930”. En Falcón, Ricardo (Ed.). Democracia, conflicto social y renovación de ideas (1916-1930), págs. 101-150. Sudamericana.

Palermo, Silvana. 2009. "Masculinidad, conflictos y solidaridades en el mundo del trabajo ferroviario en Argentina (1912-1917)". Revista Mundos do Trabalho. Publicao Eletronica Semestral do GT Mundos do Trabalho 1: 94-123.

Poy, Lucas. 2014. "Debates sobre táctica política entre socialistas y anarquistas argentinos. Una polémica entre Eduardo Gilimón y Alfredo Pasqualetti (enero-marzo de 1898)". Izquierdas 19: 1-14.

Santella, Agustín. (2000). De la revolución a la movilización. Las huelgas generales en la Argentina, 1902-2002. Notas preliminares e hipótesis. Buenos Aires: Universidad de Buenos Aires.

Suriano, Juan. (1988). Trabajadores, anarquismo y Estado represor: De la ley de residencia a la ley de defensa social (1902-1910). Buenos Aires: Centro Editorial de América Latina.

- (1991). "Estado y conflicto social: El caso de la huelga de maquinistas ferroviarios de 1912". Boletín del Instituto de Historia Argentina y Americana "Dr. Emilio Ravignani" 4: 91-115.

Zimmermann, Eduardo A. 1995. Los liberales reformistas: La cuestión social en la Argentina, 1890-1916. Buenos Aires: Sudamericana. 